\title{
Applying the Uses and Gratifications Theory to Compare Higher Education Students' Motivation for Using Social Networking Sites: Experiences from Iran, Malaysia, United Kingdom, and South Africa
}

\author{
Leila Karimi \\ International Islamic University, Malaysia \\ Rouhollah Khodabandelou \\ Universiti Putra Malaysia, Malaysia \\ Maryam Ehsani \\ Payame Noor University of Saveh, Iran \\ Muhammad Ahmad \\ University of Salford, United Kingdom
}

\begin{abstract}
Drawing from the Uses and Gratifications Theory, this study examined the Gratification Sought and the Gratification Obtained from using Social Networking Sites among Iranian, Malaysian, British, and South African higher education students. This comparison allowed to drawing conclusions about how social networking sites fulfill users' needs with different cultures. Data were collected through a quantitative study applying online and paperbased questionnaire carried out in 2013 , using a representative sample $(\mathrm{N}=320)$. Findings showed differences in students' motivation to join to and to use of social network sites in each country. Interestingly, the researchers found that cultural differences may determine the uses and gratifications of social networking sites.
\end{abstract}

Keywords: Uses and Gratification Theory; Social Networking Sites; Higher education students; Motivation

\section{Introduction}

Social networking sites (SNSs) have entered people's daily life with amazing rapidity to become an important social platform for computer-mediated communication (Correa, Hinsley, \& de Zuniga, 2010). Due to the increasing popularity of SNSs, personal social interaction with friends, family, and professional contacts has transformed itself from the offline realm into an online entity (Gallion, 2010). Hence, SNSs enable users to present themselves, connect to a social network, and develop and maintain relationships with others (Ellison, Steinfield, \& Lampe, 2007). Facebook and MySpace are successful examples (Kang \& Lee, 2010; Lipsman, 2007; Pempek, Yermolayeva, \& Calvert, 2009). 
One of the successful theoretical frameworks to examine questions of "how" and "why" individuals use media to satisfy particular needs has been the Uses and Gratifications (U\&G) Theory. Herzog (1944) and McGuire (1974) suggested that the U\&G theory has been quite successful in understanding consumers' motivations and behaviors in the context of traditional media such as radio and TV (cited in Eighmey \& McCord, 1998). Recent studies have applied the framework to new media (Flanagin, 2005; LaRose, Mastro, \& Eastin, 2001; Leung, 2001).

The extensive distribution and growth of SNSs, has drawn the attention of researchers, leading to a wide range of studies focusing on uses and social implications of SNSs. In this regard, researchers are using the U\&G theory to provide an explanation on what makes this new form of media to be so enticing, what motivated users to join in SNSs and the gratifications received from ongoing use. Applying the U\&G theory to SNSs is of vital importance in today's mass communication research because this form of mass media is relatively new in relation to radio, television, and film (Gallion, 2010).

The present study is a comparative work which employs the U\&G theory in order to understand what motivated different countries' higher education students to join SNSs and the gratifications received from ongoing use. This article also seeks to understand to what extent students seem to exhibit patterns of differences in their motivations for using SNSs. Despite the increased interest, most studies have focused on SNSs users in general or in one country neglecting to compare different countries' SNSs users mainly higher education students. The present study fills this gap by comparing four country's university students using SNSs in terms of the gratification sought and obtained that SNSs provide to them. In addition, to date the most studies in the field of U\&G theory have focused on obtained gratifications, while they have neglected to explore motivations to start using a new medium. In the review of the SNSs literature, we were able to identify several studies examining gratifications obtained (e.g., DiMicco et al., 2008; Joinson, 2008), but a few attempts have been made to examine the motivations for joining (e.g., Quan-Haase \& Young, 2010). Thus, the investigation of the motivations for joining SNSs is appropriate because it makes it clear that what influence adoption of SNSs and what kinds of gratifications users hope to obtain from the SNSs before they start using it.

To address this deficiency in the literature, the research questions are the following:

(1) What are the motivations (gratifications sought) by higher education students for joining SNSs?

(2) What are the (gratifications obtained) by higher education students for their using SNSs?

(3) Is there any difference between the students from different countries in their motivations to use SNSs?

(4) Is there any significant relationship between the frequency of using SNSs and the gratification obtained?

\section{The Uses and Gratification Theory}

The U\&G theory originated from the functionalist perspective on mass media communication (Luo, 2002) and it might be characterized by an inductive method for developing classifications 
of different motivations and functions of media use (Ruggiero, 2000; Weiser, 2001). A basic assumption of the U\&G theory is that people are actively involved in media usage and interact highly with the communication media by building profile groupings of related uses and theoretically associated gratifications (Luo, 2002). The theory describes why consumers use a particular medium and what functions the medium serves for them (Katerattanakul, 2002).

Ruggerio (2000) claimed that the U\&G theory has provided "a cutting edge approach in the initial stages of each new communication medium: newspaper, radio, television, and now the Internet" (p. 27). The theory was first developed in research on the effectiveness of the radio in the 1940s. Mainly, it focuses on the explanations for audience members' motivations and associated behaviors.

Nowadays, the appearance of computer-mediated communication has brought about the significance of uses and gratifications. With the widespread adoption of new media, such as virtual worlds and SNSs, important new research from the U\&G perspective is emerging (Ruggiero, 2000). Kaye and Johnson (2002) indicate that findings from the U\&G television studies have already been applied in Internet research. Scholars' strengthened society's understanding of the U\&G theory by making distinction between gratifications obtained and gratifications sought when they expanded the concept of gratifications (Kink \& Hess, 2008). Gratifications obtained refer to those gratifications that audience members actually experience through the use of a particular medium. By contrast, gratifications sought (also often referred to as "needs" or "motives") refer to those gratifications that audience members expect to obtain from a medium before they have actually come into contact with it. Research shows that gratifications obtained are a better predictor of media use than gratifications sought and that if a medium meets or exceeds the gratifications sought by a user, recurrent use will occur (Palmgreen \& Rayburn, 1979). Researchers indicated that understanding the gap between these two types of gratifications is important for analyzing how different audience members use various kinds of media, the expectations that they bring to their media habits, and the gratifications they actually obtain from their exposure to a diverse array of media products.

When it comes to user behavior and motivation, the U\&G theory has been the most common approach, explaining "why" certain media behavior occurs. Users are seen as goal-oriented, with rationales for their use (and non-use) of various media (Brandtzæg \& Heim, 2009). Katz and other scholars believed that the U\&G is grounded in the idea that users have certain reasons and motivations for selecting media and intentionally choose a certain message source that best fits their own personal needs. The theory suggests that users have numerous media options to choose from and suggests that the reasons and motivations for selecting a specific media will vary from user to user (Katz, Blumer, \& Gurevitch, 1974). McQuail (1984) proposed the idea of "user taste" when examining the selection of media, which suggested that users choose the media based on personal preferences and motivations and that media are simply a means to achieve an end goal.

In order to understand audiences' motivations and behaviors, the U\&G theory has been divided into two major parts. The first part, researchers have argued the factors that can predict motivations for media usage. Several researchers have addressed motivations for using media by applying demographic factors such as income, education, age (Cho et al., 2003; Choi, Kim, \& McMillan, 2009) and psychological context (Fahr \& Boecking, 2005; Hausman \& Siekpe, 2009). Applying demographic variables, Wang, Fink, and Cai (2008) compared gender between different types of motivations of media use. Females are more likely to use media to satisfy 
their lack of family relationships. In contrast, males chose to use media for removing their feeling of loneliness. Moreover, a study conducted by Cho et al., (2003) on the U\&G of Internet by age and socio-economic variables indicates that age differences have an influence on engagement of Internet behavior and motivation. They found that individuals who are young and come from high socioeconomic levels have a tendency to use the Internet as their desired gratification, while those who are young and come from lower socioeconomic background use the Internet to gain their learning gratifications. A research conducted by Fahr and Boecking (2005) shows the psychological effects of emotional influence on being interested or not being interested in a television program or how people escape from a program. They indicated that individuals with having negative emotions, such as loss, anxiety, and boredom, are more likely to switch a program after they feel unpleasant.

Regarding the second part, researchers focus on understanding the audiences' behavior and motivation. Katz, Gurevitch, \& Hass (1973) clarified that their motivations to consume media are derived from five specific needs: (a) Cognitive needs which is related to "strengthening information, knowledge, and understanding" (p. 167); (b) Affective needs that is related to "strengthening aesthetic, pleasurable and emotional experience" (p. 167); (c) Integrative needs which is to "strengthening credibility, confidence, stability, and status" (p. 167); (d) Social integrative needs which relates to "strengthening contact with family, friends, and the world" (p. 167); and (e) Escape or tension release needs which helps to escape or release tension from society and self.

\section{Uses and Gratifications Theory and Social Networking Sites}

With the rise of SNSs such as blogs, Facebook, Twitter, Flickr, and YouTube, users have become constantly connected and capable of interacting with one another (Ding \& Zhang, 2010). Boyd and Ellison (2007) describe SNSs as web-based services that allow individuals to: (1) create personal profiles including self-descriptions within an online community; (2) publicly show a list of other users with who they share a connection, and (3) within a system. SNSs are considered by Ellison et al. (2007) as online spaces that allow individuals to present themselves, articulate their social networks, and establish or maintain connections with others [all within an online environment]".

Even though SNSs are new, in the past few years, several researchers began to pay attention by studying them. Mass communication researchers are using the U\&G theory to provide an explanation as to why users find this new form of media to be so enticing. They have focused on how individuals are using SNSs. What motivates them to start using SNSs and why they continue to use them? It is necessary to consider users' motives and researchers have suggested several possible motives for the use of SNSs. Previous research suggests that the gratifications sought from social media could be anything from a place for information distribution to a venue for feedback to a platform to promote organizations or even an opportunity to participate in a community of connected individuals (Stassen, 2010).

When specifically examining Facebook and MySpace by Raacke and Bonds-Raacke (2008) very popular U\&G for having either account included to keep in touch with old friends, to keep in touch with current friends, to post/look at pictures, to make new friends, and to locate old friends. Less commonly reported uses and gratifications included to learn about events, to post social functions, to feel connected, to share information about yourself, and about academic and dating purposes. In a study conducted by Santos, Hammond, Durli, and Chou (2009), it was 
reported the students' motivations for using SNSs for the Singaporean students suggesting students used these sites primarily to socialize. A significant percentage $(42 \%)$ used SNSs to both keep in touch with friends and 'have fun'.

In another instance, Acquisti and Gross (2006) indicated that Facebook user's motivation is to learn about their classmates and keep in touch with them but they denied it for dating activities. Also, Clark, Lee and Boyer (2007) found a similar finding in their study of Facebook motivation among college students. They use Facebook to stay in touch with their friends and family. Moreover, Facebook helps them to pass time and be entertained. Pempek et al.'s (2009) researched about the Facebook experience and its motivation among college students. They found that motivations for using Facebook among students are reported as facilitating social relationships with their friends rather than parents and strangers. A number of studies (Lampe, Ellison, and Steinfield, 2006; Sheldon, 2008; Joinson, 2008; Subrahmanyam, Reich, Waechter, \& Espinoza, 2008; Pempek et al., 2009; Reich, Subrahmanyam, \& Espinoza, 2012; Tosun, 2012) reported that nurturing or maintaining existing relationships has been the most mentioned motivation for using Facebook, the seeking new ones also has been a frequently mentioned objective for using Facebook. In demonstrating gender differences on SNSs usage, Tufekci and Spence (2007) found that women have more interests in interpersonal relationships online for keeping existing relationships while men use SNSs for seeking new friends and those who share the same interests. In addition, men have more friends in SNSs than women.

Other motives that have been sometimes reported include enhancing one's reputation (being cool), avoiding loneliness, keeping tabs on other people, (seeing who has joined on Facebook or what they are doing), and entertainment (Joinson, 2008; Sheldon, 2008; Tosun, 2012). In using the U\&G theory, Haridakis and Hanson (2009) also found in their study that socially active, young males used YouTube as a ready form of entertainment, using YouTube to fulfill entertainment needs such as thrill-seeking and information-seeking (p. 329).

In reviewing the literature, the most remarkable factors of the U\&G in relation to SNSs were found by Ancu \& Cozma (2009), LaRose \& Eastin (2004), and Park, Kee, \& Valenzuela (2009). By examining a group of 1,715 college students, they found the four major uses and gratification factors of SNS users to be: socializing, entertainment, self-status seeking, and information. LaRose and Eastin (2004) found similar factors like the need for information-seeking, entertainment, and social needs to be the most prevalent (p. 360-361). Likewise, Ancu and Cozmo's (2009) study about the U\&G in using Facebook reported that gratifications sought were (1) a desire for social interaction, (2) information seeking and (3) entertainment. These factors will construct the umbrella of main topics for research within all the following literature. A large amount of SNSs users find gratification in the amount of information allotted to them through SNSs (Park et al., 2009, p. 731). According to Park et al. (2009), Facebook users seek out information about on- and off-campus events and political and civic issues (p.732). In relation to political issues, two-thirds of all Americans participate in an SNSs and nearly half of these users used an SNS to provide political information during the 2008 Presidential Race (Ancu \& Cozma, 2009, p. 570) along with allowing the user to "be friend to their politician" (Ancu \& Cozma, 2009, p. 567). In their findings, Ancu and Cozma (2009) found that in response to seeking out political information on MySpace, 67 percent of MySpace users chose the SNS because they could socially interact with their chosen presidential candidate and other political supporters (p. 574-576). Additional gratifications obtained from Facebook usage besides sociability and social information includes: killing time, affection, fashion, and share problems (Quan-Haase \& Young, 2010). 


\section{Method}

\section{Sample}

A sample of 320 respondents was initially recruited from four countries' higher education students using SNSs including Iran, Malaysia, the UK, and South Africa. A total of 240 survey questionnaire was hand-delivered to Malaysian and Iranian students from which 74 (68\%) Malaysian and $96(80 \%)$ Iranian students responded to the questionnaires. Furthermore, a total of 470 messages containing the link of online questionnaire which was administered through the Google Doc online survey provider over a period of three month were posted to the UK and South Africa students from which only 61 UK students and a total of 89 South African students responded to the online questionnaire. The final survey sample had a mean age of 24.11 years $(S D=5.41)$, ranging from 18 to 45 years. Fifty three percent of the respondents were male, and $47 \%$ of the respondents were female. The justification for selecting four different countries' university students is because students are belonged to different cultures and they may have differences or similarities in terms of motivations for joining SNSs and the gratifications received from ongoing use.

\section{Procedures}

To collect data, the study was divided into two strategies. The first one was that the online questionnaire link was sent via message to students of the UK and the South Africa. The survey, by identifying the students' profiles that had joined to universities' pages on Facebook as the most popular example of SNSs, posted messages to the British and African students regarding the request for filling the online questionnaire. This afforded the opportunity to access a large number of students while they were actually using the site. The second alternative was the questionnaire which was distributed among Iranian and Malaysian students. The questionnaire was previously validated for content and face validity through a pilot test involving 28 students at a local Iranian university. We used the online and the handdelivered questionnaire over a three-month period from December 10, 2012 to February 27, 2013. The same questionnaire was administered to students in all countries. For Iranian students the survey questionnaire was translated into Farsi (Persian) language and then backtranslated into English by two Iranian bilingual individuals to assure comparability. For other respondents, the English version of the questionnaire was used. The researchers explained the purpose of this study and respondents were requested to complete the questionnaires.

\section{Measurement}

The survey was divided into three sections with 46 questions: demographic information, gratification sought, and gratification obtained items. The first section consisted of seven items. Respondents were asked to indicate their gender, age, and nationality. In order to obtain a measure of respondents' experience with the sites, they were asked to indicate the number of SNSs that they have account, how long they had been using SNSs, the average amount of time they spent on SNSs per day and the size of their SNSs friends list. The second section examined motivations or gratification sought for joining SNSs which was taken and modified from (Quan-Haase \& Young 2010). The measure consisted of one item with 11 options, which covered a wide range of motivations that respondents could choose from. In 
the third section, gratification obtained measured the range of benefits that students obtained from their use of the SNSs. To assess respondents' motivations for using SNSs, 27 items were adopted from Papacharissi and Rubin (2000) list of gratification obtained. The respondents were asked to respond about the different reasons why they use SNSs and they could rate each item on a 5-point Likert-type scale ranging from (1 strongly disagree to 5 strongly agree). Although the questionnaire items were originally created for indicating reasons people use the Internet, they are applicable to the present study because similar gratifications are expected to motivate their use. Respondents were asked to complete the phrases such as "I use Social Network......." The questionnaire is divided into 6 categories: interpersonal utility, academic aims, information seeking, communication, financial, and entertainment.

\section{Results}

This study first investigated gratification sought and gratification obtained from using SNSs by different countries' higher education students. It continued to investigate the difference between students in their gratification obtained in using SNSs and the relationship between the frequency of using SNSs and the gratification obtained.

\section{Social Networking Sites Usage}

Prior to examining the research questions, descriptive information on SNSs usage among respondents was obtained. The respondents' use of SNSs includes four variables: (1) years of using SNSs, (2) time consumption, (3) number of friends, and (4) the number of SNSs they have accounts. As for the duration of SNSs usage, most students, $60.4 \%$ of Iranian, $75.7 \%$ of Malaysia; $67.2 \%$ of UK, and $70.8 \%$ of South Africa have used SNSs over 2 years on average. In findings on respondents' daily use of SNSs showed that most respondents on average, Iranian (79.2\%), Malaysian (68.9\%), UK (70.5\%), and South African (68.5\%) respondents reported logging into their SNSs accounts for more than 30 minutes per day. Again, data could suggest that most respondents use SNSs extensively, they may have more free time to use SNSs. The frequency statistics are provided in Table 1.

Table 1. Social Networking Sites Usage

\begin{tabular}{lcccccccc}
\hline Variable & \multicolumn{2}{c}{ Iran } & \multicolumn{2}{c}{ Malaysia } & \multicolumn{2}{c}{ UK } & \multicolumn{2}{c}{ South Africa } \\
\hline Years of using SNSs & $\mathbf{N}$ & $\%$ & $\mathbf{N}$ & $\%$ & $\mathbf{N}$ & $\%$ & $\mathbf{N}$ & $\%$ \\
\hline Less than 6 months & 8 & 8.3 & 1 & 1.4 & 2 & 3.3 & 3 & 3.3 \\
6 months to 1 year & 11 & 11.5 & 6 & 8.1 & 6 & 9.8 & 7 & 7.8 \\
1 year to 2 years & 19 & 19.8 & 11 & 14.8 & 12 & 19.7 & 16 & 17.9 \\
2 years and more & 58 & 60.4 & 56 & 75.7 & 41 & 67.2 & 63 & 70.8 \\
\hline
\end{tabular}

\section{Time consumption on}

SNSs

\begin{tabular}{lcccccccc} 
Less than 10 minutes & 5 & 5.2 & 0 & 0 & 1 & 1.6 & 4 & 4.5 \\
$10-20$ minutes & 5 & 5.2 & 7 & 9.5 & 6 & 9.8 & 10 & 11.2 \\
$21-30$ minutes & 10 & 10.4 & 16 & 21.6 & 11 & 18.0 & 14 & 15.7 \\
More than 30 minutes & 76 & 79.2 & 51 & 68.9 & 43 & 70.5 & 61 & 68.5 \\
\hline
\end{tabular}




\begin{tabular}{lcccccccc}
$\begin{array}{l}\text { Number of friends } \\
\text { Less than } 50\end{array}$ & 20 & 20.8 & 7 & 9.5 & 4 & 6.6 & 1 & 1.1 \\
$51-100$ & 12 & 12.5 & 9 & 12.2 & 10 & 16.4 & 3 & 3.4 \\
$101-150$ & 23 & 24.0 & 11 & 14.9 & 8 & 13.1 & 18 & 20.2 \\
$151-200$ & 14 & 14.6 & 15 & 20.3 & 9 & 14.8 & 8 & 9.0 \\
$201-500$ & 17 & 17.7 & 26 & 35.1 & 18 & 29.5 & 30 & 33.7 \\
More than 501 & 10 & 10.4 & 6 & 8.1 & 12 & 19.7 & 29 & 32.6 \\
\hline & & & & & & & & \\
Number of SNSs & & & & & & & & \\
Facebook & 78 & 81.2 & 70 & 94.6 & 61 & 100 & 89 & 100 \\
My space & 19 & 19.8 & 20 & 27.1 & 24 & 39.3 & 14 & 15.7 \\
Twitter & 26 & 27.1 & 40 & 54.1 & 33 & 54.1 & 58 & 65.2 \\
Google plus & 35 & 36.4 & 48 & 64.9 & 42 & 68.9 & 63 & 70.1 \\
Linked in & 8 & 8.3 & 23 & 31.1 & 32 & 52.5 & 40 & 44.9 \\
\hline
\end{tabular}

In addition, the table also demonstrates that out of the total respondents, $17.7 \%$ of Iranian, $35.1 \%$ Malaysia, $29.5 \%$ of the UK, and $33.7 \%$ South African respondents reported fell into social networking friendship with 201-500 friends.

A notable difference between African and other respondents, however, was found in the number of connections included in their friends list. Of the total African respondents, $32.6 \%$ reported having over 501 social connections in their friends list. It was followed by $33.7 \%$ of them reported having 201-500 friend in their friends list in compare to other three groups, whereas their Iranian counterparts $20.8 \%$ reported having less than 50 connections in their friends list. This implies that Africans may be more inclusive in their network construction whereas their Iranian counterparts may be more exclusive in their network building.

For the number of SNSs the data illustrate that, while respondents may have many accounts at the same time Facebook ranked as the most popular SNSs used most frequently by $81 \%$ of Iranian, $97 \%$ of Malaysian, $100 \%$ of UK and $100 \%$ of South Africa respondents, followed by Google plus, Twitter and Myspace. The adoption of Facebook by students is a trend that results from a need to be fashionable. The need to communicate with friends over SNSs occurs part of the peer group as well as a larger societal trend.

\section{Research Questions}

\section{Research Question 1: What are the reported motivations (gratifications sought) by students for joining SNSs?}

In examining the first research question, descriptive analysis was performed to determine the different motivations reported by higher education students to join SNSs and how they differ across the four countries. As demonstrated in Table 2 below, a total of 11 items were identified (Friend suggested it, Everyone I know use SNSs, Keeping in touch with others, Find classmates, Received a promotional e-mail, Get to know more people, Network in general, Find course information, Find people with mutual interests, Find jobs, Find dates), reflecting the most important motives for joining SNSs. 
CONTEMPORARY EDUCATIONAL TECHNOLOGY, 2014, 5(1), 53-72

Table 2. Users' Motivations in Joining SNSs

\begin{tabular}{|c|c|c|c|c|c|c|c|c|c|c|c|}
\hline & $\begin{array}{c}\text { Friend } \\
\text { suggested it }\end{array}$ & $\begin{array}{c}\text { Everyone } \\
\text { I know } \\
\text { using } \\
\text { SNS }\end{array}$ & $\begin{array}{l}\text { Keeping in } \\
\text { touch with } \\
\text { others }\end{array}$ & $\begin{array}{c}\text { Find } \\
\text { classmates }\end{array}$ & $\begin{array}{c}\text { Received a } \\
\text { promotional } \\
\text { e-mail }\end{array}$ & $\begin{array}{c}\text { Get to } \\
\text { know more } \\
\text { people }\end{array}$ & $\begin{array}{l}\text { Network } \\
\text { in } \\
\text { general }\end{array}$ & $\begin{array}{l}\text { Find course } \\
\text { information }\end{array}$ & $\begin{array}{c}\text { Find } \\
\text { people } \\
\text { with } \\
\text { mutual } \\
\text { interests }\end{array}$ & $\begin{array}{l}\text { Find } \\
\text { jobs }\end{array}$ & $\begin{array}{l}\text { Find } \\
\text { dates }\end{array}$ \\
\hline Iran & $81 \%$ & $66 \%$ & $51 \%$ & $20 \%$ & $4 \%$ & $18 \%$ & $20 \%$ & $4 \%$ & $17 \%$ & $3 \%$ & $8 \%$ \\
\hline Malaysia & $78 \%$ & $62 \%$ & $53 \%$ & $30 \%$ & $9 \%$ & $25 \%$ & $18 \%$ & $9 \%$ & $19 \%$ & $11 \%$ & $12 \%$ \\
\hline UK & $84 \%$ & $55 \%$ & $43 \%$ & $25 \%$ & $6 \%$ & $20 \%$ & $15 \%$ & $11 \%$ & $14 \%$ & $10 \%$ & $7 \%$ \\
\hline $\begin{array}{l}\text { South } \\
\text { Africa }\end{array}$ & $73 \%$ & $44 \%$ & $45 \%$ & $10 \%$ & $4 \%$ & $26 \%$ & $19 \%$ & $8 \%$ & $16 \%$ & $22 \%$ & $18 \%$ \\
\hline
\end{tabular}


Of the total sample; $81 \%$ of Iranian, $78 \%$ of Malaysian, $84 \%$ of UK, and $73 \%$ of Sought African respondents revealed that "A friend suggested it" as the major motivation for joining SNSs. It indicates that friendship networks play an important role in the ultimate adoption of SNSs, considering that SNSs' primary purpose is social connectivity (Boyd, 2006; Boyd \& Heer, 2006). Once a person has joined an SNS, the need to communicate with his or her friends and family occurs over SNSs and therefore suggests it to others. The second motivation chosen frequently by Iranian (66\%), Malaysian (62\%), UK (55\%), and South African (44\%) respondents was "Everyone I know is using SNSs." The third item respondents chose most often 51\% of Iranian, $53 \%$ of Malaysian, $43 \%$ of UK and $45 \%$ of South African respondents was the item of "Keeping in touch with others." This item was followed by "Find classmates," with $20 \%, 30 \%, 25 \%$, and $10 \%$ respectively. These two items reflect a need for social connectivity that is met through SNSs and allows its users to stay freely connected with friends and family and to be part of the larger SNSs community. Table 2 indicates that the other motivations "Find jobs", "Find dates", and "Received a promotional e-mail" were selected much less frequently by respondents as reasons to join SNSs.

\section{Research Question 2: What are the (gratifications obtained) by higher education students for their use of SNSs?}

The present study was also designed to consider the motives for SNSs usage (Figure1 and Table 3). The following section gives a description of the 5 categories derived from the literature (Interpersonal utility, Pass time, Entertainment, Information seeking, Convenience), reflecting the most important motives for using SNSs.

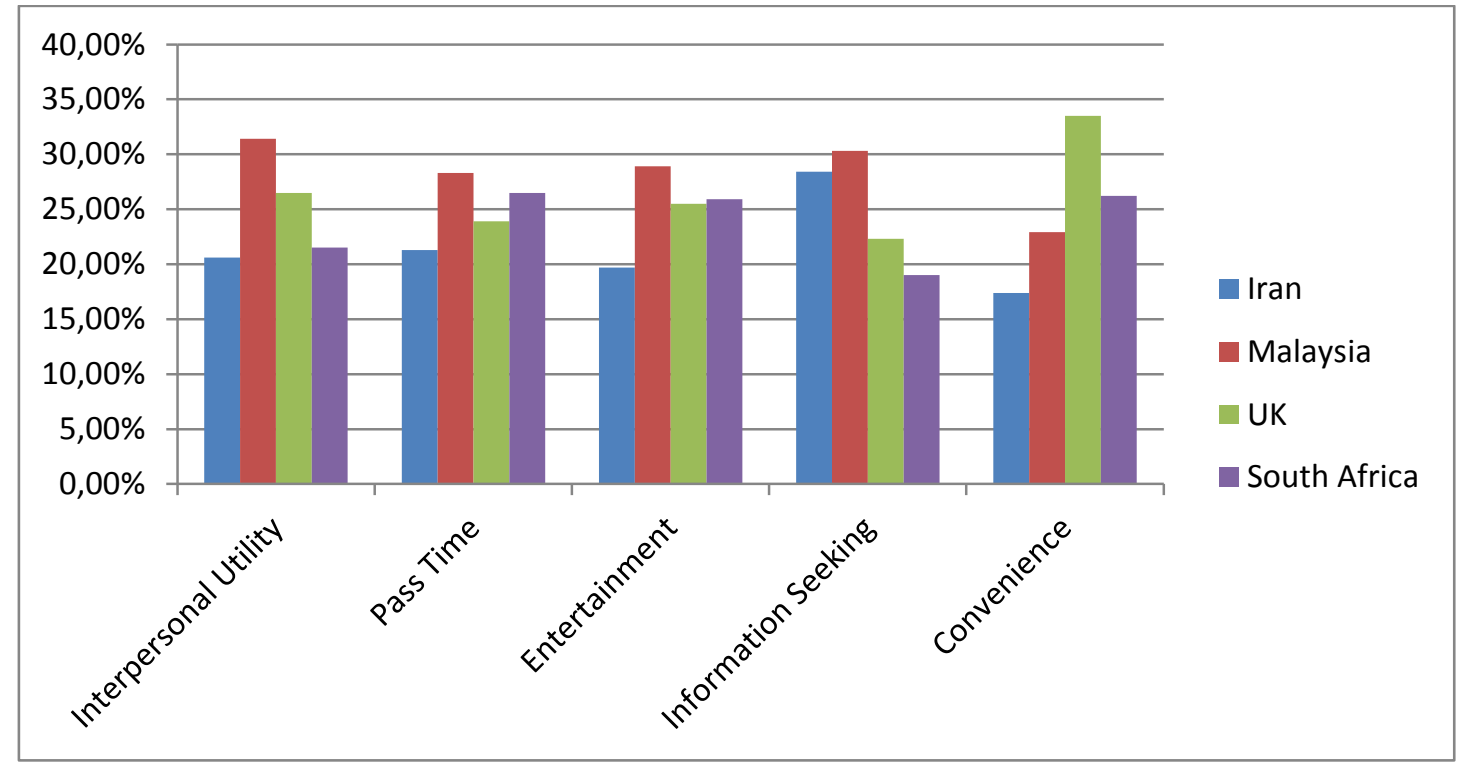

Figure 1. Overview over the User Motivations in SNSs (\%)

In the following paragraphs, frequencies and percentages for each country's respondents are reported respectively. 
Iran: Iranian students reported "Information seeking" (28.40\%), as the key gratification obtained by using SNSs. "Pass time" $(21.30 \%)$, Interpersonal utility (20.60\%), Entertainment $(19.70 \%)$, and Convenience $(17.40 \%)$ have been the other gratifications reported by them respectively.

Malaysia: The most important reasons for Malaysian in using SNSs were claimed to be "Interpersonal Utility" (31.40\%), followed by "Information seeking" (30.30\%), "Entertainment (29.90\%), "Pass time" (28.30\%), and "Convenience" (22.90\%) respectively.

UK: Among the UK students "Convenience" (33.50\%), was identified to be the main reason for using SNSs. "Interpersonal Utility" (26.50\%), "Entertainment" (25.50\%), "Pass time' (23.90\%) and "Information seeking" (22.30\%) then were chosen to be the other motivations for using SNSs.

South Africa: African students reported that the key reasons for using SNSs were 'Pass time' (26.50\%), "Convenience' (26.20\%), and "Entertainment" (25.90\%). On the other hand, "Interpersonal Utility" (21.50\%) and "Information seeking" (19\%) were the factors identified by South African students to be the less important in using SNSs.

Table 3. User Motivations in SNSs Use

\begin{tabular}{lccccc}
\hline & $\begin{array}{c}\text { Interpersonal } \\
\text { Utility }\end{array}$ & Pass Time & Entertainment & $\begin{array}{c}\text { Information } \\
\text { Seeking }\end{array}$ & Convenience \\
\hline Iran & $20.60 \%$ & $21.30 \%$ & $19.70 \%$ & $28.40 \%$ & $17.40 \%$ \\
Malaysia & $31.40 \%$ & $28.30 \%$ & $28.90 \%$ & $30.30 \%$ & $22.90 \%$ \\
UK & $26.50 \%$ & $23.90 \%$ & $25.50 \%$ & $22.30 \%$ & $33.50 \%$ \\
South & $21.50 \%$ & $26.50 \%$ & $25.90 \%$ & $19 \%$ & $26.20 \%$ \\
Africa & & &
\end{tabular}

- Percentage of participants in the questionnaire who responded "strongly agree" and "agree" to the items

The study also seeks to compare male and female students' opinions regarding the motives for using SNSs. The results are shown in Table 4.

Table 4. Male and Female Motivations in SNSs Use

\begin{tabular}{lll}
\hline & Male & Female \\
\hline Interpersonal utility & $55.2 \%$ & $44.8 \%$ \\
Pass time & $51 \%$ & $49 \%$ \\
Entertainment & $55.3 \%$ & $44.7 \%$ \\
Information Seeking & $57.2 \%$ & $42.8 \%$ \\
Convenience & $53.1 \%$ & $46.9 \%$ \\
\end{tabular}

As shown in Table 4, male students reported that the most important reasons for using SNSs were information seeking $(57.20 \%)$, followed by entertainment $(55.30 \%)$, interpersonal utility (55.20\%), convenience $(53.10 \%)$, and pass time (51\%) respectively. While, female students' 
reasons for using SNSs were pass time (49\%), convenience $(46.90 \%)$, interpersonal utility (44.80\%), entertainment (44.70\%), and information seeking (42.80\%) respectively.

\section{Research Question 3: Is there any differences between the students from different countries in their motivations to use SNSs?}

Since the equal variance assumption has been violated, Welch and Brown-Forsythe test was applied to check differences level between four countries' higher education students in their motivations in using SNSs.

Table 5. Descriptive Statistics

\begin{tabular}{lccc}
\hline & $\mathbf{N}$ & Mean & SD \\
\hline Iran & 96 & .1571 & .05585 \\
Malaysia & 74 & .6142 & .28931 \\
UK & 61 & .6312 & .28363 \\
South Africa & 89 & .6849 & .27113 \\
Total & 320 & .5000 & .32670 \\
\hline
\end{tabular}

If the $\mathrm{F}$ ratio is found to be significant with either the Welch statistic or the Brown Forsythe statistic, an appropriate post hoc test would be required. Using the Welch statistic, we found that $[F(3,126.431)=209.110, p<.001]$. Furthermore, using the Brown-Forsythe test, we found that $[F(3,213.998)=88.497, p<.001]$. Based on these findings, it can be concluded that the adjusted $\mathrm{F}$ ratio is significant. Hence we can conclude that there is a difference among higher education students in their motivations in using SNSs. Since the $p$ value is smaller than the alpha, the null hypothesis is rejected so we would have permission to proceed and compare the group means (Table 6).

Table 6. Welch and Brown-Forsythe Test for Equality of Means

\begin{tabular}{lcccc}
\hline & Statistic $^{\mathrm{a}}$ & df1 & df2 & Sig. \\
\hline Welch & 209.110 & 3 & 126.431 & .000 \\
Brown-Forsythe & 88.497 & 3 & 213.998 & .000 \\
\hline
\end{tabular}

a. Asymptotically F distributed.

One should look at Table 7 only when found a significant difference in Welch and BrownForsythe test; that is, if the Sig. value was equal to or less than .05. The post-hoc tests in this table tell exactly where the differences among the groups occur. Look down the column labelled Mean Difference. Look for any asterisks ( $\left.{ }^{*}\right)$ next to the values listed. When found an asterisk, this means that the two groups compared are significantly different from one another at the $p<.05$ level. The exact significance value is given in the column labelled Sig. In the results presented in Table 7, only Iranian students group is significantly different from three other groups. That is, the Iranian students differ significantly in terms of their motivation in using SNSs. 
Table 7. The Post-hoc Tests

\begin{tabular}{llccc}
\hline \multirow{2}{*}{$(\mathrm{I})$ Country } & \multicolumn{1}{c}{$(\mathrm{J})$ Country } & Mean Difference (I-J) & Std. Error & Sig. \\
\hline \multirow{3}{*}{ Iran } & Malaysia & $-.45713^{*}$ & .03661 & .000 \\
& UK & $-.47416^{*}$ & .03875 & .000 \\
& South Africa & $-.52778^{*}$ & .03483 & .000 \\
Malaysia & Iran & $.45713^{*}$ & .03661 & .000 \\
& UK & -.01703 & .04093 & .976 \\
& South Africa & -.07065 & .03724 & .231 \\
UK & Iran & $.47416^{*}$ & .03875 & .000 \\
& Malaysia & .01703 & .04093 & .976 \\
& South Africa & -.05362 & .03934 & .524 \\
South Africa & Iran & $.52778^{*}$ & .03483 & .000 \\
& Malaysia & .07065 & .03724 & .231 \\
& UK & .05362 & .03934 & .524 \\
\hline
\end{tabular}

*The mean difference is significant at the .05 level.

Based on the above results, it can be concluded that a Welch and Brown-Forsythe test was conducted to explore difference between students in their motivations for using SNSs. Respondents were divided into four groups according to their country of living (Group 1: Iranian; Group 2: Malaysian; Group 3: the UK; Group 4: South African). There was a statistically significant difference at the $p<.05$ level in their motivation to join SNSs for the four higher education student groups: $[F(3,126.431)=209.110, p<.001]$. Post-hoc comparisons using the Tukey HSD test indicated that only the mean score for Iranian Students $(M=0.157, S D=0.558$, $p<.001$ ) was significantly different from the other three groups. Other groups did not differ significantly from each other.

\section{Research Question 4: Is there any significant relationship between the frequency of using SNSs and the gratification obtained?}

Table 8 indicates that a comparison was made using Pearson's ( $r$ ) on the relationship between motivation scores and time spending on SNSs. The result of the comparison indicated that 320 respondents show a significant, low, and negative correlation at $p<0.05(r=-0.095$, significant at the 0.05 level, $N=320$ ). It can be concluded that the correlation between variables is negative which means that when time of spending in SNSs increases the motivation of using SNSs will reduce. However, they are statistically significant. The magnitude of correlation between variables is $r=0.095$ which is, according to Guilford's Rules of Thumb, a low and small relationship. Therefore, time spending on SNSs was not a significant predictor for motivation of using SNSs. 
Table 8. Correlational Matrix for Motivation and Time Spending

\begin{tabular}{llrr}
\hline & & Motivation & Time Spending \\
\hline \multirow{3}{*}{ Motivation } & Pearson Correlation & 1.00 & $-0.095 * *$ \\
\cline { 2 - 2 } & Sig. (1-tailed) & & 0.045 \\
& $\mathrm{~N}$ & 320 & 320 \\
\multirow{3}{*}{ Time Spending } & Pearson Correlation & $-0.095^{* *}$ & 1.00 \\
& Sig. (1-tailed) & 0.045 & \\
& $\mathrm{~N}$ & 320 & 320 \\
\hline
\end{tabular}

** Correlation is significant at the 0.05 level (1-tailed).

\section{Discussion}

Current study employed the U\&G theory in order to understand what motivated different countries' higher education students to join SNSs and the gratifications obtained from ongoing use. This study produced results which corroborate the findings of a great deal of the previous work in the field. In years of using SNSs, most respondents have been using them for more than 2 years. In finding respondents on time consumption with SNSs per day also showed that most respondents reported logging into their SNSs accounts for more than 30 minutes a day. When questioned about the number of SNSs, data revealed a high degree of popularity of Facebook in comparison with other SNSs among students in four countries. This article focuses on university students' motivations for joining and continuing use of SNSs. It became apparent that there was a diverse and wide-ranging variety of reasons why higher education students join and visit SNSs regularly.

The results of gratification sought for joining SNSs identified "a friend suggested it", "everyone I know is using SNSs", "keeping in touch with others" as the three key gratifications that students sought for joining SNSs. This result is in line with many studies including Raacke and Bonds-Raacke (2008), Durli and Chou (2009), Acquisti and Gross (2006), Clark, Lee, and Boyer (2007), Pempek et al. (2009) indicating the factor of keeping in touch with friends is one of the primary reasons to join SNSs. This item was followed by other notable motivations such as "find classmates", "get to know more people", "network in general", "find course information" and "find people with mutual interests" as the rest of options which accounted for a high percentage of selection by the respondents.

The result of this part is in same direction with the Raacke and Bonds-Raacke (2008) findings when examining Facebook and MySpace, which indicated that uses and gratifications for having either account included to keep in touch with old friends, to keep in touch with current friends, and to make new friends or to get to know more people. However, less commonly reported uses and gratifications included dating purposes in this study and the other study conducted by Acquisti and Gross (2006) indicating that Facebook users denied using SNS for dating activities. These results conform the findings of the current study, suggesting "find jobs", "find dates", "received a promotional e-mail" were selected much less frequently by respondents as reasons to join SNSs. Based on our findings on gratifications sought, we conclude that social gratifications lead to adoption with higher education students' wanting to be active members of their community by reaching out to their peer network. 
It is important to note that the most striking finding from the analysis show that SNSs in all countries fulfill different gratifications sought and obtained for users, suggesting that this difference arises from different cultures. These differences are central to the way in which users experience SNSs and use them. For Iranian students, "information seeking" emerged as a key factor for using SNSs that was reported to be the second motivation for using SNSs among Malaysian students. It was not reported by the rest of the students from the two other nationalities (UK and South Africa) to be very significant. SNSs here, for Iranian, are used to look for information, to get information for free, to seek new way to do research, to find out about social events and to see what is out there. This finding is similar to result of the study conducted by Park et al. (2009) which revealed that a large amount of SNSs users find gratification in the amount of information allotted to them through SNSs. According to him SNSs users seek out information about on- and off-campus events. This study also is consistent with the study by LaRose and Eastin (2004) which found similar factors like the need for information-seeking, entertainment, and social needs to be the most prevalent. A similar finding was provided by Ancu and Cozmo (2009) who noted about the U\&G in using Facebook, indicating information seeking as the second significant factor reported by users. Additionally, Haridakis and Hanson (2009) also found similar motivation for using YouTube as an example of social media. They found that users using YouTube to fulfill their needs such as informationseeking. However this study is in contrast with the findings of Raacke and Bonds-Raacke (2008) with less commonly reported uses and gratifications included learning about social events. Therefore, information seeking emerges as a key difference of Iranian students in using SNSs with the rest of students.

Among majority of Malaysian students the most important reason for using SNSs were claimed to be "interpersonal utility" that was stated to be the second motivation for using SNSs among UK students. It seems that this motivation was not reported by Iranian and African students to be very significant. Interpersonal utility factor in using SNSs, for Malaysian here, means to participate in discussions, to show others encouragement, belong to a group, to enjoy answering questions, to express themselves freely, to give input, to get more points of view, to tell others what to do, to know about what other people say and do, to meet new people and to help others. However, interpersonal utility is not discussed clearly in the literature, this study is in line with Acquisti and Gross (2006) study which indicated that Facebook user's motivation is to learn about their classmates. The other motives that have been sometimes reported include enhancing knowing what they are doing (Joinson, 2008; Sheldon, 2008; Tosun, 2012). The result of this study is also in direction with many studies including Raacke and Bonds-Raacke (2008) that reported very popular uses and gratifications for having either account in SNSs included to make new friends. This study also revealed that users are not so interested in sharing information about themselves. In the same vein, many studies (Lampe, Ellison, and Steinfield, 2006; Joinson, 2008; Pempek et al., 2009; Reich, Subrahmanyam, \& Espinoza, 2012; Sheldon, 2008; Subrahmanyam, Reich, Waechter, \& Espinoza, 2008; Tosun, 2012) reported that seeking new friends has been another frequently mentioned objective for using Facebook.

Additionally, many of the UK higher education students highlighted "convenience" motivation to be the main reason for using SNSs. The convenience motivation suggests the important aspect of SNSs in understanding what makes an online social venue attractive for the UK students. This factor was identified by Sought African students to be the second motivation to use SNSs. Apparently, this factor does not seem to be highly significant among Iranian and Malaysian students. Convenience factor for the UK students means to communicate with 
friends and family, it is cheaper, it is easier to e-mail than tell people, people don't have to be there to receive e-mail. Perhaps due to the convenient access to a variety of communicative capabilities facilitating social connections as well as other Internet activities, students turn to such sites as a personal hub on the Internet. The result of this part is similar to study of Clark, Lee, and Boyer (2007), Raacke and Bonds-Raacke (2008), Santos, Hammond, Durli, and Chou (2009) who found a similar finding in their studies for Facebook usage motivation among college students. Majority of students in their study highlighted using SNS particularly Facebook as a mean to stay in touch with their old and current friends and family. However, the study conducted by Pempek et al. (2009) in some extent is in contrast with the result of the current study in terms of UK college students. They found that motivations for using SNS particularly Facebook among students was facilitating social relationships with their friends, but not a proper means to contact parents.

Furthermore, university students in South Africa reported that the most important reason for using SNSs was "pass time". However, the factor of passing time seems to be the second motivation of using SNSs among Malaysian. Seemingly, this factor does not seem to be weighty among Iranian students. Pass time factor for African students means to be passes time when bored, when have nothing better to do and to occupy personal time. In the same vein, Clark, Lee, and Boyer (2007) also found a similar finding which supports the result of this part. They claimed that Facebook helps college students to pass time and to be entertained. Similarly, Quan-Haase and Young (2010) findings showed that killing time was one of the motivations for using SNS among users.

The study also compared male and female students' opinions regarding the motives for SNSs use. Interestingly, the most important reason for male students to use SNSs was information seeking which is line with study of Haridakis and Hanson (2009) who found that males used YouTube to fulfill entertainment needs such as thrill-seeking and information-seeking, while this factor indicated to be less important for female students. Furthermore, the less important motive in using SNSs reported to be pass time for male students. In contrast, the factor of pass time was identified by majority of females to be the primary motive of using SNSs.

The findings for the current research suggested that there are differences between university students from different countries in their motivations in using SNSs. However, only Iranian students were significantly different from the other three groups. Furthermore, the findings also show that there is a significant, low, and negative correlation between motivation of use and time spending on SNSs which means that when time of spending in social network sites increases the motivation of using SNSs will reduce.

\section{Conclusion and Recommendations}

Theoretically, this study expands the uses and gratifications perspective to the new media SNSs which have become popular among higher education students all around the world. Students from different countries engage differently in online activities. The justification for this claim is that they have dissimilar cultures which lead to the different motivations to join and use SNSs. Hence, cultural differences determine the U\&G of social networks.

The results of this study imply new directions for further research. Future research should include a cultural dimension in order to produce better contexts for results. Studies should be conducted to investigate other countries with diverse and larger samples (e.g., teens and 
young adults not enrolled in college), leading to new insights on the cultural impact of the U\&G in SNSs on other age groups. In addition to quantitative research methodologies, future research also needs more qualitative methodologies to collect data about higher education students' motivation to join and use SNSs. While the present study contributes to the emerging body of literature on SNS, U\&G and cross-country research, the study is not without limitations. The unbalanced sample ratio and the limited number of each country's sub-sample might limit the generalizability of the findings of this study. Thus, a more balanced sample as well as the larger sample size should be employed in future studies.

\section{References}

Acquisti, A. \& Gross, R. (2006). Imagined communities awareness, information sharing, and privacy on the Facebook. Retrieved on 14 May 2013 from http://petworkshop.org/ 2006/preproc/preproc_03.pdf

Ancu, M. \& Cozma, R. (2009). Myspace politics: Uses and gratifications of befriending candidates. Journal of Broadcasting \& Electronic Media, 53(4), 567-583.

Boyd, D. (2006, December). Friends, Friendsters, and MySpace top 8: Writing community into being on social network sites. Retrieved on 14 May 2013 from http://131.193.153.231/ www/issues/issue11_12/boyd/index.html

Boyd, D. \& Heer, J. (2006). Profiles as conversation: Networked identity performance on Friendster. Proceedings of the Hawaii international conference on system sciences (HICSS-39). Kauai, HI.

Boyd, D. M \& Ellison, N. B. (2007). Social network sites: Definition, history, and scholarship. Journal of Computer-Mediated Communication, 13(1), 210-230.

Brandtzæg, P. B. \& Heim, J. (2009). Why people use social networking sites. In A. A. Ozok \& P. Zaphiris (Eds.), Online communities and social computing (pp. 143-152). Berlin: Springer.

Cho, J., De Zuniga, H. G., Sueng, A., Nhumane, A., Hyunseo, H., \& Rojas, H. (2003). Beyond access: Digital divide, Internet use and gratifications gained. Paper presented at the annual meeting of the International Communication Association. Marriott Hotel, San Diego, CA.

Choi, Y., Kim, J., \& McMillan, S. (2009). Motivators for the intention to use mobile TV. International Journal of Advertising, 28(1), 147-167.

Clark, N., Lee, S., \& Boyer, L. (2007). A place of their own: An exploratory study of college students' uses of Facebook. Paper presented at the annual meeting of the International Communication Association. San Francisco, CA.

Correa, T., Hinsley, A. W., \& de Zuniga, H. G. (2010). Who interacts on the web? The intersection of users' personality and social media use. Computers in Human Behavior, 26(1), 247-253.

DiMicco, J.M., Millen, D.R., Geyer, W., Dugan, C., Brownholtz, B., \& Muller, M. (2008). Motivations for social networking at work. Paper presented at the ACM conference on computer supported cooperative work. San Diego, CA.

Ding, H. \& Zhang, J. (2010). Social media and participatory risk communicationduring the H1N1 flu epidemic: A comparative study of the United States and China. China Media Research, 6(4), 80-91. 
Eighmey, J. \& McCord, L. (1998). Adding value in the information age: Uses and gratifications of sites on the world wide web. Journal of Business Research, 41, 187-194.

Ellison, N., Steinfield, C., \& Lampe, C. (2007). The benefits of Facebook "friends": Social capital and college students' use of online social network sites. Journal of Computer-Mediated Communication, 12, 1143-1168.

Fahr, A. \& Boecking, T. (2005). Programmed escape? Avoidance processes in TV -program choices. Retrieved on 29 May 2013 from http://www.allacademic.com/meta/p13345 _index.html

Flanagin, A. J. (2005). IM online: Instant messaging use among college students. Communication Research Reports, 22(3), 175-187.

Gallion, A . J. (2010). Applying the Uses and Gratifications Theory to Social Networking Sites:A Review of Related Literature. Retrieved on 29 May 2013 from http://www.academia. edu/1077670/Applying_the_Uses_and_Gratifications_Theory_to_Social_Networking_Sit es_A_Review_of_Related_Literature

Haridakis, P. \& Hanson, G. (2009). Social interaction and co-viewing with YouTube: Blending mass communication receptions and social connection. Journal of Broadcasting \& Electronic Media, 53(2), 317-335.

Hausman, A. \& Siekpe, J. (2009). The effect of web interface features on consumer online purchase intentions. Journal of Business Research, 62(1), 5-13.

Herzog, H. (1944). What do we really know about day-time serial listeners? In P. Lazarsfeld \& F. Stanton (Eds.), Radio research 1942-1943. New York: Duel, Sloan and Pearce.

Joinson, A. (2008). Looking up, looking at or keeping up with people? Motives and use of Facebook. Paper presented at the twenty-sixth annual SIGCHI conference on human factors in computing systems. New York.

Kang, Y. S. \& Lee, H. (2010). Understanding the role of an IT artifact in online service continuance: An extended perspective of user satisfaction. Computers in Human Behavior, 26, 353-364.

Katerattanakul, P. (2002). Framework of effective website design for business-to-consumer internet commerce, INFOR, 40(1), 57-69.

Katz, E., Gurevitch, M., \& Hass, H. (1973). On the use of mass media for important things. American Sociological Review, 38, 164-181.

Katz, E., Blumer, J. G., \& Gurevitch, M. (1974). Utilization of mass communication by the individual. In J. G. Blumler \& E. Katz (Eds.), The uses of mass communications: Current perspectives on gratifications research (pp. 19-34). London: SAGE.

Kaye, B. \& Johnson, T. (2002). Online and in the know: Uses and gratifications of the Web for political information. Journal of Broadcasting \& Electronic Media, 46(1), 54.

Kink, N. \& Hess, T. (2008). Search engines as substitutes for traditional information sources? An investigation oaf media choice. Information Society, 24(1), 18-29.

Lampe, C. Ellison, N., \& Steinfield, C. (2006). A Face(book) in the crowd: Social searching vs. social browsing. Paper presented at the 20th anniversary conference on computer supported cooperative work. New York. 
LaRose, R. \& Eastin, M. S. (2004). A social cognitive theory of internet uses and gratifications: Toward a new model of media attendance. Journal of Broadcasting \& Electronic Media, $48(3), 358-377$.

LaRose, R., Mastro, D., \& Eastin, M. S. (2001). Understanding Inter-net usage: A social-cognitive approach to uses and gratifications. Social Science Review, 19, 395-413.

Leung, L. (2001). College student motives for chatting on ICQ. New Media \& Society, 3(483500).

Lipsman, A. . (2007). Social networking goes global. Retrieved on 27 May 2013 from http://www.comscore.com/press/release.asp?press $=1555$

Luo, X. (2002). Uses and gratifications theory and e-consumer behaviors: A structural equation modeling study. Journal of Interactive Advertising, 2(2). Retrieved on 29 May 2013 from http://jiad.org/article22.html

McGuire, J. (1974). Psychological motives and communication gratification. In J. Blumler \& E. Katz (Eds.), The uses of mass communications. Beverly Hills, CA: Sage.

McQuail, D. \& Windahl, S. (1993). Communication models for the study of mass communication. London: Longman.

Palmer, N., Batola, J., Jones, M., \& Baron, S. (2008). Social networking sites within higher education: Threat or opportunity? Retrieved on 29 May 2013 from http://www.engsc. ac.uk/downloads/scholarart/ee2008/p038-palmer.pdf

Palmgreen, P. \& Rayburn, J. D. (1979). Uses and gratifications and exposure to public television: A discrepancy approach. Communication Research, 6, 155-180.

Papacharissi, Z. \& Rubin, A. M. (2000). Predictors of Internet use. Journal of Broadcasting \& Electronic Media, 44, 175-196.

Park, N. Kee, K., \& Valenzuela, S. (2009). Being immersed in social networking environment: Facebook groups, uses and gratifications, and social outcomes. CyberPsychology \& Behavior, 12(6), 729-733.

Pempek, T., Yermolayeva, Y., \& Calvert, S. (2009). College students' social networking experiences on Facebook. Journal of Applied Developmental Psychology, 30(3), 227-238.

Quan-Haase, A. \& Young, A. (2010). Uses and gratifications of social media: A comparison of Facebook and instant messaging. Bulletin of Science, Technology \& Society, 30(5), 350 361.

Raacke, J. \& Bonds-Raacke, J. (2008). MySpace and Facebook: Applying the uses and gratifications theory to exploring friend -networking sites. Cyber Psychology \& Behavior, 11(2), 169-174.

Reich, S. M., Subrahmanyam, K., \& Espinoza, G. (2012). Friending, IMing, and hanging out faceto-face: Overlap in adolescents' offline and online social networks. Developmental Psychology, 48(2), 356-368.

Ruggiero, T. (2000). Uses and gratification theory in the 21st century. Mass Communication \& Society, 3(1), 3-37.

Santos, I., Hammond, M., Durli, Z., \& Chou, S.-Y. (2009). Is there a role for social networking sites in education? In A. Tatnall \& A. Jones (Eds.), Education and technology for a better world (pp. 321-330). Berlin Heidelberg: Springer. 
Sheldon, P. (2008). The relationship between unwillingness-to-communicate and students' Facebook use. Journal of Media Psychology, 20(2), 67-75.

Stassen, W. (2010). Your news in 140 characters: Exploring the role of social media in journalism. Global Media Journal, 4(1), 1-16.

Subrahmanyam, K., Reich, S. M., Waechter, N., \& Espinoza, G. (2008). Online and offline social networks: Use of social networking sites by emerging adults. Journal of Applied Developmental Psychology, 29, 420-433.

Tosun, L. P. (2012). Motives for Facebook use and expressing "true self" on the Internet. Computers in Human Behavior, 28, 1510-1517.

Tufekci, Z. \& Spence, K. (2007). Online social network sites: A gendered inflection point in the increasingly social web? Paper presented at the annual meeting of the American Sociological Association. New York. Retrieved on 29 may 2013 from http://www. allacademic.com/meta/p182984_index.htm

Wang, Q., Fink, E., \& Cai, D. (2008). Loneliness, gender, and parasocial interaction: A uses and gratifications approach. Communication Quarterly, 56(1), 87-109.

Weiser, E. B. (2001). The functions of Internet use and their social and psychological consequences. Cyber Psychology \& Behavior, 4(6), 723-742.

Correspondence: Rouhollah Khodabandelou, Department of Foundation Education, Faculty of Educational Studies, Universiti Putra Malaysia, Serdang, Selangor, Malaysia 